\title{
Правовые и организационные аспекты маркетинговой деятельности в учреждениях угомовно-испоннитемьной системы
}

\author{
А. А. КОЛЬЕВ - доцент кафедры управления экономической деятельностью \\ и организации производства в уголовно-исполнительной системе инженер- \\ но-экономического факультета ВИПЭ ФСИН России, кандидат экономиче- \\ ских наук, доцент;
}

М. В. СУХАРЕВА - начальник отдела трудовой адаптации осужденных УФСИН России по Вологодской области

\section{Ре ферат}

Целью работы является рассмотрение особенностей маркетинговой деятельности в учреждениях УИС в правовом и организационном ракурсе, предметом - маркетинговая деятельность в УИС как комплекс организационно-производственных и коммерческо-сбытовых мероприятий. В статье рассмотрены результаты реформирования промышленного сектора УИС, процесс образования центров трудовой адаптации осужденных и производственных (трудовых) мастерских, актуальность развития маркетинговой деятельности в УИС; представлено описание проблем организации производственной, в том числе маркетинговой, деятельности в учреждениях УИС, связанной с реализацией положений Федерального закона от 05.04.2013 № 44-Ф3 «О контрактной системе в сфере закупок товаров, работ, услуг для обеспечения государственных и муниципальных нужд» и других нормативно-правовых актов. Основным результатом проведенного исследования является разработка предложений, направленных на изменение нормативно-правовой базы и реализацию мероприятий организационного характера для повышения уровня трудовой занятости осужденных, эффективности маркетинговой и производственной деятельности учреждений УИС. Представленный опыт может быть использован специалистами и руководителями учреждений и органов УИС, занимающимися вопросами организации производственной и маркетинговой деятельности, а также учеными, проводящими исследования в данной сфере.

Ключевы е слова: уголовно-исполнительная система; центры трудовой адаптации осужденных; маркетинговая деятельность в УИС; правовое регулирование закупок; организация производства в УИС; привлечение осужденных к труду.

12.00.11 - Судебная деятельность, прокурорская деятельность, правозащитная и правоохранительная деятельность

\section{Legal and organizational aspects of marketing in penitentiary institutions}

\begin{abstract}
A. A. KOLYEV - Associate Professor of the Department of Economic Management and Organization of Production in the Penal System of the Vologda Institute of Law and Economics of the Federal Penal Service of Russia, PhD. in Economics, Associate Professor;
\end{abstract}

M. V. SUKHAREVA - Head of the Department of Labor Adaptation of Convicts of the Federal Penal Service of Russia in the Vologda Region

Abstract

The aim of this study is to consider the features of marketing activities in the penal institutions in a legal and organizational perspective, the subject is marketing activities in the penal system as a complex of organizational, production and commercial marketing activities. The article considers the results of reforming the industrial sector of the penal system, the process of formation of labor adaptation centers for convicts and production (labor) workshops, the relevance of the development of marketing activities in the penal system; a description of the problems of organizing production, including marketing, activities in the institutions of the penal system, related to the implementation of the 
provisions of the Federal Law dated 05.04.2013 No. 44-FZ "On the contract system in the field of procurement of goods, works, services to meet state and municipal needs" and other legal acts. The main result of the study is the development of proposals aimed at changing the regulatory framework and the implementation of organizational measures to increase the level of employment of convicts, the effectiveness of marketing and production activities of penal institutions. The experience presented can be used by specialists and heads of institutions and bodies of the penal system dealing with the organization of production and marketing activities as well as scientists conducting research in this area.

Key words: penal system; centers for labor adaptation of convicts; marketing activities in the penal system; legal regulation of procurement; organization of production in the penal system; attraction of convicts to work.

12.00.11 - Judicial activities, prosecution activities, human rights and law enforcement

В последнее время в уголовно-исполнительной системе осуществляется реформирование промышленного сектора, направленное на переориентацию его деятельности на решение социальных задач, связанных с адаптацией человека к нормальной жизни после освобождения из мест лишения свободы.

В ходе реформирования предприятия исправительных учреждений реорганизованы в структурные подразделения этих учреждений - центры трудовой адаптации осужденных (далее - ЦТАО) и производственные (трудовые) мастерские, основными задачами которых являются:

- организация трудового воспитания осужденных путем привлечения их к общественно полезному оплачиваемому труду;

- создание условий для моральной и материальной заинтересованности осужденных в результатах труда;

- восстановление и закрепление профессиональных и трудовых навыков осужденных, необходимых им для последующей скорейшей адаптации в обществе.

Однако решение вопросов, связанных с обеспечением финансового благополучия ЦТАО, невозможно без организации производственно-сбытовой деятельности на маркетинговой основе. На современном этапе развития рыночной экономики бюджетные учреждения являются неотъемлемыми ее участниками. Ввиду отсутствия бюджетного финансирования расходов на функционирование ЦТАО и производственных (трудовых) мастерских основным источником их финансового обеспечения становятся средства, полученные от реализации выпускаемой продукции. Эффективное развитие данных структурных подразделений учреждений, исполняющих наказания, как базы для реализации целей уголовно-исполнительного законодательства в части привлечения осужденных к труду, привития им трудовых навыков во многом определяется сохранением и развитием маркетинговой деятельности в УИС - комплекса организационно-производственных и коммерческосбытовых мероприятий, направленных на повышение конкурентоспособности выпускаемой учреждениями продукции, решение проблем ее эффективной реализации с целью обеспечения трудовой занятости осужденных и создания дополнительных рабочих мест [2, с. 12].

Обычно маркетинг ассоциируется со сбытом продукции, но на практике органы и учреждения УИС часто сталкиваются с необходимостью изучения рынка продавцов с целью эффективного обеспечения потребности подразделений в материально-технических ресурсах [1, с. 68].

Привлекательность учреждений УИС в качестве коммерческих партнеров объясняется рядом причин:

- достаточно высокой экономической стабильностью и надежностью, обусловленной тем, что в УИС существенное внимание уделяется вопросам эффективности управления государственным имуществом, контролю за его сохранностью;

- особым режимом охраны предприятий и их материальной базы, создающим ограниченный доступ посторонних на территорию;

- минимальными расходами на развитие социальной сферы;

- низкой стоимостью рабочей силы;

- наличием свободных производственных мощностей, оборудования и инфраструктуры.

Однако на практике при организации производственной, в том числе маркетинговой, деятельности в учреждениях УИС возникает значительное количество проблемных вопросов правового и организационного плана.

Так, в соответствии с действующим законодательством главное условие работы ЦТАО - это его полная самоокупаемость, позволяющая гарантированно обеспечи- 
вать своевременную выплату обязательных платежей осужденным, в том числе по заработной плате. Существующий механизм привлечения к труду не предусматривает прямого финансирования из федерального бюджета на обеспечение трудовой занятости осужденных. На администрацию учреждения ложится обязанность не только трудоустроить осужденных, но еще и найти конкретного платежеспособного потребителя конечной продукции, за счет поступления денежных средств от которого будут погашены коммунальные платежи, выплачена заработная плата, оплачено сырье, проведены ремонтные работы и т. д. Для минимального воспроизводства необходимо и наличие финансового результата, что в условиях рыночной экономики и обеспечения производства учреждений УИС материальными ресурсами в рамках действующей редакции (от 27.06.2019) Федерального закона от 05.04.2013 № 44-Ф3 «О контрактной системе в сфере закупок товаров, работ, услуг для обеспечения государственных и муниципальных нужд» (далее - 44-Ф3) не представляется возможным.

Во-первых, 44-ФЗ предполагает осуществление закупок конкурентными способами. При закупке материалов учреждения УИС проводят аукционы, что значительно затягивает сроки закупки и поставки (зачастую они составляют более месяца), и это не устраивает потенциальных заказчиков, приводит к снижению эффективности участия пенитенциарных учреждений в конкурсных процедурах на электронных площадках и уменьшению их конкурентоспособности в сравнении с организациями других форм собственности по причине сжатости заявленных потенциальными заказчиками сроков поставки продукции по полной стоимости. В этой связи большинство частных предпринимателей, у которых есть возможность купить товары по более низкой цене, на данные аукционы не выходят.

Следует отметить, что если требования 44-Ф3 для государственных и муниципальных организаций направлены на экономию бюджетных средств и прозрачность закупок, то применение данных требований к центрам трудовой адаптации, осуществляющим производственную и торговую деятельность в условиях рынка и заинтересованным в быстрой закупке качественного и дешевого сырья, материалов, услуг, лишь затрудняет работу.

Такое применение закона приводит к увеличению доли услуг, оказываемых сторонними организациями, и снижению объемов собственного производства, поскольку в рамках действующего законодательства учреждениям УИС крайне сложно обеспечить бесперебойность производственного процесса, который затрудняется длительными сроками проведения конкурентных процедур на закупку материалов, обеспечивающих исполнение основного государственного контракта. Это относится, прежде всего, к горюче-смазочным материалам и запасным частям к технике и производственному оборудованию.

Во-вторых, проведение независимой экспертизы при закупке материалов и комплектующих на основании п. 12 ч. 1 ст. 93 44-Ф3 приводит к увеличению затрат и повышению конечной цены готовой продукции.

Кроме того, заказчик (конечный приобретатель) продукции в силу действия в п. 11 ч. 1. ст. 93 44-Ф3 у единственного поставщика аналогичным образом обязан провести независимую экспертизу поставляемого товара, что также увеличивает расходы по его приобретению и снижает привлекательность данных закупок на рынке. В итоге расходы на обязательное проведение независимой экспертизы увеличивают себестоимость и уменьшают рентабельность выпускаемой продукции.

В связи с этим в рамках существующего правового поля необходимо определить целесообразность проведения такого рода независимых экспертиз в таком формате.

С организационной точки зрения, учреждениям УИС следует проводить детальный анализ расходов на производство продукции. Это позволит выявить, какие затраты какими решениями обусловлены, что в дальнейшем в отношении их может быть предпринято, а также решить целый ряд вопросов, таких как выбор рентабельных заказов, планирование будущих направлений деятельности, распределение и минимизация затрат, состав сметы и анализ отклонений. Применение различных методик позволит проанализировать затраты на производство одной единицы продукции, осуществить контроль за обоснованностью включения всех затрат, а также их размером и в конечном итоге оптимизировать затраты на производство продукции и снизить ее конечную стоимость [3, с. 490-492]. Кроме того, исправительные учреждения, являющиеся непосредственными производителями продукции, имеют реальную возможность снизить конечную цену изделия за счет исключения затрат, возникающих при закупках через посредников, что особенно актуально в настоящее время. 
В-третьих, в Постановлении Правительства Российской Федерации от 14.07.2014 № 649 (ред. от 04.02.2016) «О порядке предоставления учреждениям и предприятиям уголовно-исполнительной системы преимуществ в отношении предлагаемой им цены контракта» предусмотрен узкий перечень товаров (работ, услуг), в соответствии с которым при определении поставщиков (подрядчиков, исполнителей) заказчик обязан предоставлять учреждениям и предприятиям УИС преимущества в отношении предлагаемой им цены контракта.

Однако в данном перечне отсутствует ряд товаров, которые производятся в учреждениях: профилированный металлический лист, пиломатериалы, мебель для офисов, мебель металлическая, одежда трикотажная, специальная одежда. В этой связи мы предлагаем внести изменения в нормативно-правовую базу и расширить перечень товаров (работ, услуг), в соответствии с которым при определении поставщиков (подрядчиков, исполнителей) заказчик обязан предоставлять учреждениям и предприятиям УИС преимущества в отношении предлагаемой им цены контракта.

В-четвертых, требования Федерального закона от 29.12.2012 № 275-Ф3 (ред. от 27.12.2018) «О государственном оборонном заказе» накладывают на поставщиков сырья, реализующих его учреждениям в ходе исполнения государственных контрактов в рамках государственного оборонного заказа (продовольствие, вещевое имущество), обязанность открывать лицевые счета в органах федерального казначейства для обеспечения прозрачности операций, что, несомненно, ограничивает круг соответствующих организаций.

В-пятых, отсутствует законодательно утвержденный механизм взаимодействия пенитенциарной системы с бизнес-сообществом по организации совместных производств, в том числе и в части применения системы льготного налогообложения. Также действующее законодательство не позволяет передавать коммерческим организациям производственные объекты недвижимого имущества учреждений без проведения конкурсов или аукционов. Срок проведения конкурсов или аукционов с учетом необходимых согласований с вышестоящими органами составляет от двух до шести месяцев, что приводит к отказу коммерческой организации - потенциального партнера от намерения сотрудничать с учреждением УИС.

Следует отметить, что правовые и организационные аспекты маркетинговой де- ятельности в учреждениях УИС тесно связаны с организацией их производственной деятельности в целом, а также с привлечением осужденных к оплачиваемому труду в частности.

Так, на сегодняшний день для учреждений УИС актуальна проблема отсутствия достаточного объема гарантированного государственного и муниципального заказа. Ее решение позволило бы дополнительно трудоустроить осужденных на оплачиваемые работы. В настоящее время законодательно закреплены положения о государственной поддержке учреждений УИС в части размещения заказов для удовлетворения государственных нужд. Данная норма содержится в ст. 10 и 10.1 Закона Российской Федерации от 21.07.1993 № 5473-1 (ред. от 06.02.2019) «Об учреждениях и органах, исполняющих уголовные наказания в виде лишения свободы», предусматривающих участие Правительства Российской Федерации в организации производственной деятельности, а также участие органов государственной власти субъектов Российской Федерации в обеспечении трудовой занятости осужденных за счет средств бюджетных ассигнований собственных бюджетов. Однако широкого применения данные нормативные положения не получили. Результаты взаимодействия с главами муниципальных образований в настоящее время не оказывают значительного влияния на сложившуюся ситуацию. Так, по итогам работы за 2018 г. для нужд муниципальных учреждений Вологодской области отгружено продукции и оказано услуг лишь на 3,5 млн руб. Поиск заказов на производство товаров, выполнение работ, оказание услуг с целью привлечения осужденных к труду осуществляется учреждениями УИС самостоятельно. При этом более половины доходов от привлечения осужденных к труду исправительные учреждения получают от сторонних коммерческих организаций, которые не являются государственными и муниципальными заказчиками.

Тем не менее региональная поддержка является одним из значимых условий для развития и повышения эффективности пенитенциарного производства. Положительный опыт в данной сфере уже имеется. Так, УФСИН России по Республике Карелия совместно с Государственным комитетом по управлению государственным имуществом и организации закупок Республики Карелия успешно апробирован проект по осуществлению закупок товаров, работ, услуг у исправительных учреждений региона как единственного поставщика в рамках 
перечня, утвержденного постановлением Правительства Российской Федерации от 26.12.2013 № 1292. В связи с этим до заказчиков, осуществляющих конкурентным способом централизованные закупки товаров (работ, услуг), которые включены в указанный перечень, комитетом доведено требование о том, чтобы все заявки на закупку содержали официальный отказ УФСИН России по Республике Карелия в поставке необходимой продукции. В результате указанной работы в 2017 г. исправительными учреждениями Республики Карелия со стороны региональных и муниципальных органов власти получен портфель заказов на сумму более 40,5 млн руб.

В целом проведение совместно с органами государственной власти работы, направленной на повышение эффективности трудового использования осужденных, не только положительным образом скажется на развитии пенитенциарного производства, но и будет иметь своим следствием снижение рецидивной преступности, а также стабилизацию социально-экономической обстановки в регионе.

Следующей важной проблемой промышленного сектора УИС является значительный износ основных производственных фондов. Продукция, производимая на оборудовании со значительным износом, имеет высокую себестоимость, что не позволяет учреждениям УИС конкурировать с другими производителями и быть полноценными участниками рынка.

Много проблемных моментов в настоящее время в учреждениях УИС связано с привлечением осужденных к оплачиваемому труду. Так, в соответствии с п. 4 ст. 99 УИК РФ осужденные, получающие заработную плату, возмещают стоимость питания, одежды, коммунально-бытовых услуг и индивидуальных средств гигиены ежемесячно в пределах фактических затрат, произведенных в данном месяце. Из этих средств осуществляются также погашение исков и выплата алиментов. Однако размер удержаний не стимулирует осужденных к труду. Кроме того, работающие и неработающие осужденные содержатся в одинаковых условиях. Разница заключается лишь в том, что с работающих осужденных производится удержание понесенных расходов на их содержание из заработной платы, а за неработающих и не имеющих определенного дохода осужденных платит государство. Заметим, что величина заработка, подлежащего зачислению на лицевой счет конкретного осужденного, имеет для него весомое значение и является одним из важнейших аспектов мотивации к труду, ведь дополнительные денежные средства позволяют осужденным помогать своим семьям, накапливать сбережения для адаптации после выхода на свободу.

Проблема привлечения осужденных к оплачиваемому труду связана также с отсутствием у многих из них рабочих профессий. Само по себе данное обстоятельство не является ограничивающим фактором при трудоустройстве спецконтингента на оплачиваемые работы, однако в процессе привлечения осужденных к труду возникают разногласия с органами прокуратуры, которые признают факты привлечения осужденных, в том числе низкоквалифицированных специалистов, к работе без документов, подтверждающих наличие у них профессии (специальности), нарушениями действующего законодательства. Вместе с тем срок отбывания наказания осужденных в колониях-поселениях для лиц, впервые осужденных к лишению свободы, и текучесть спецконтингента в колониях общего и строго режима с учетом наполняемости и количества учебных групп не позволяют в сжатые сроки обучить всех трудоспособных.

Кроме того, в настоящее время на федеральном уровне отсутствуют установленные законодательством нормы, позволяющие коммерческим организациям, использующим в своей производственной деятельности труд осужденных, реализовывать указанные товары в рамках п. 11 ч. 1. ст. 93 44-Ф3 в статусе единственного поставщика. Законодательное закрепление данных норм значительно увеличило бы заинтересованность бизнеса в вовлечении осужденных в трудовые процессы.

Решением проблемы трудоустройства осужденных может послужить и осуществление мероприятий по реконструкции и техническому перевооружению действующих производств, таких как монтаж на существующей производственной базе технологических линий по производству новых конкурентоспособных видов изделий, имеющих спрос на региональном рынке.

Основываясь на том, что одним из основных направлений производственной деятельности в УФСИН России по Вологодской области является швейное производство, мы можем утверждать, что реализация мероприятий по закупке современного швейного оборудования для нужд пенитенциарных учреждений позволит обеспечить гарантированное создание новых рабочих мест для трудоустройства осужденных. 
И, наконец, одной из главных организационных проблем маркетинговой деятельности учреждений УИС является оптимизация штатной численности аттестованных сотрудников ЦТАО, которая выразилась в сокращении должностей работников маркетинговых служб во многих исправительных учреждениях. Это привело к нехватке грамотных специалистов из числа аттестованных сотрудников, в функциональные обязанности которых входят вопросы организации производственного процесса, в том числе управления маркетинговой деятельностью.

В этой связи необходимо рационально перераспределить между сотрудниками
ЦТАО учреждений УИС обязанности, в том числе связанные с маркетинговой деятельностью, организовать обучение сотрудников, ответственных за данное направление.

Имеющиеся сегодня проблемы в осуществлении производственной и маркетинговой деятельности учреждений УИС требуют разработки конкретных практических мер в правовом и организационном плане. Предложенные изменения нормативно-правовой базы и решение накопившихся организационных вопросов позволят повысить уровень трудовой занятости осужденных, эффективность маркетинговой и производственной деятельности учреждений УИС.

\section{СПИСОК ЛИТЕРАТУРЫ}

1. Алексеев, А. П. Организация трудовой адаптации осужденных : учебное пособие / А. П. Алексеев. - Владимир : ВЮИ ФСИН России, 2016. - 92 с. - ISBN 978-5-93035-592-5.

2. Кирьянова, Е. С. Актуальные проблемы маркетинговой деятельности в уголовно-исполнительной системе / Е. С. Кирьянова // Актуальные проблемы пенитенциарной науки и практики. - 2015. - № 2 (4). - С. 11-13.

3. Тарасова, И. А. Научно обоснованные подходы к определению стоимости производимой в уголовно-исполнительной системе продукции / И. А. Тарасова // Международный пенитенциарный форум «Преступление, наказание, исправление» (к 20-летию принятия Конституции Российской Федерации) : сборник тезисов выступлений участников мероприятий форума (Рязань, 5-6 декабря 2013 г.). - Рязань : Академия ФСИН России, 2013. - С. 490492. - ISBN 978-5-7743-0648-0.

\section{REFERENCES}

1. Alekseev A. P. Organizaciya trudovoj adaptacii osuzhdennyh [Organization of labor adaptation of convicts]. Vladimir, 2016. 92 p. (In Russ.).

2. Kir'yanova E. S. Aktual'nye problemy marketingovoj deyatel'nosti v ugolovno-ispolnitel'noj sisteme [Actual problems of marketing in the penal system]. Aktual'nye problemy penitenciarnoj nauki i praktiki - Actual problems of penal science and practice, 2015, no. 2(4), pp. 11-13. (In Russ.)

3. Tarasova I. A. Nauchno obosnovannye podhody k opredeleniyu stoimosti proizvodimoj v ugolovno-ispolnitel'noj sisteme produkcii [Scientifically sound approaches to determining the value of products manufactured in the penal system]. Sbornik tezisov vystuplenij uchastnikov meropriyatij mezhdunarodnogo penitenciarnogo foruma «Prestuplenie, nakazanie, ispravlenie» ( $k$ 20-letiyu prinyatiya Konstitucii Rossijskoj Federacii) [A collection of abstracts by participants in the events penal of the international penitentiary forum "Crime, Punishment, Correction" (on the 20th anniversary of the adoption of the Constitution of the Russian Federation)]. Ryazan, 2013, pp. 490-492. (In Russ.). 